\title{
Collaborative strategic planning: improving consciousness of belonging and resilience
}

\author{
I. Rossetti \\ University of Venice, Italy
}

\begin{abstract}
This case, as a part of a Ph.D. dissertation on the professional knowhow of collaborative policies, concerning Roma V 2030, a strategic planning policy on the territory of the fifth Rome municipality. This experience starts from the assumption that strategic planning can be defined as a collective building of a shared vision for the future of a given territory, through processes of participation, discussion and listening. It is indeed a pact between directors, actors, citizens and other partners to achieve this vision through a strategy and a series of subsequent projects to improve resilience. From March until October 2015, the fifth Rome municipality implemented a strategic planning process in order to adopt a resilient policy instrument and to deepen its knowledge of the territory, sharing tools with the communal offices of Rome, which is one of the 100 Resilient Cities of the socalled international project of the Rockefeller Foundation. The idea to develop a territorial investigation and to look to the next fifteen years comes from the municipality who has to consider the daily stimuli of its citizenship, often referring to urgent and contingent needs, in a broader framework of local policies. The aim of the study is to highlight the importance of the adaptability of professional practices of the professionals and practitioners involved in the process. Additionally, the sense of belonging, as an aim of strategic planning, especially in those geographically reformed urban contexts in need of experiencing forms of regeneration and renewal is investigated.
\end{abstract}

Keywords: strategic planning, public policies, resilience, collaborative approaches. 


\section{Introduction}

Collaborative strategic planning requires a team of different professional figures that should have the ability to merge their expertise and different points of view to achieve optimal results [1].

Coordination is indisputably, the most important process; it is fundamental to guide the different actors and stakeholders, firstly, in a process of responsibility assumption, that should evolve in the implementation of projects, or in competences they have to impact the commons.

The objective of the study is the analysis of the role of the researcher and her colleagues in a collaborative strategic planning in the context of a public Italian administration.

Risks, resources, problems and opportunities relating to very local strategic policies, as well as the local political context have been analysed.

This paper starts from wider considerations, elucidated in Section 2, relating to the $\mathrm{PhD}$ research developed by the writer, about the professional, we call planner, and his/her characteristics.

In Section 3, the case will be exposed with its conditions, while in Section 4 we can better understand the outcomes and the role of belonging in strategic planning.

In the last section, some reflections will take into account the previous elements to elaborate how strategies, resilience and belonging are very important tools for professionals and practitioners of planning.

\section{What is a planner}

The planner is here defined as a practitioner of inclusive territorial public policies and planning. He/she is here intended as a third figure having the role of guarantor of process' effectiveness, transparency and efficiency. The aim of the $\mathrm{PhD}$ research, which the experience here described is a part of, is not the unambiguous definition of what planning is, but some of its features we call knowhow or skills of planning practitioners, able to promote the effective implementation of these policies.

In a case study where a public institution is the developer of a process, this last one is accompanied by formal roles of practitioners as integrated consultants. In this specific case the above-mentioned features are observed; they fall into three main areas: relational, technical and political.

These intertwine and overlap continuously with each other, building a common characteristic that we will define as interaction, in Bourdieu's concept of field [2, p. 97].

In analytic terms, a field may be defined as a network, or a configuration, of objective relations between positions. These positions are objectively defined, in their existence and in the determinations they impose upon their occupants, agents, or institutions, by the present and potential situation (situs) in the structure of the distribution of species of power (or capital) whose possession commands access to the specific profits that are at stake in the field, as well as 
their objective relation to other positions (domination, subordination, homology, etc.).

Interaction - and thus the interactivity of practitioners - is an element for building a relationship between individuals who exercise some form of reciprocity on each other. At the same time, professional's interaction defines an important contribution to knowledge in processes. In the first case, therefore, we can define the planner as interlocutor, in the second as an expert. The third definition describes the planner's political and transversal role, as a mediator.

\subsection{Planner as an interlocutor: relational area}

Promotion and reception of relationships, to provide an operational network of actors and stakeholders, is one of the planner's main functions. These interactions are vectors for which the planning practitioner represents the starting or ending point.

The role of the practitioner is strongly related to his/her authority and mostly to his/her credibility and legitimacy: these feelings come out since the very first interaction with other interlocutors (actors, stakeholders, citizens, etc.). Forester [3] underlines the difference between recognition and acknowledgments in the contact between subjects, because in the second case they converge to a common path.

What gives more tangibility, to define relationships between interlocutors with different roles, can also be:

- corporeality, as consciousness of bodies in space;

- a strategic and organizational approach to inclusive processes, strengthening non-ephemeral interactions, acknowledgement-based.

\subsection{Planner as an expert: technical area}

An expert is here considered as a professional, owner of a store of knowledge allowing understanding different languages, whether idioms or specific areas of expertise. Technical skills thus constitute the store of knowledge (history, institutions, sociology and culture, urbanism, laws, etc.) needed to produce interpretations. They are even more complex and complete with a multidisciplinary group approach, for managing technical languages and, specifically, dominate the encoded tools for citizenship inclusion.

An expert needs the experience of developing his/her own interpersonal skills too, by education and application of the knowledge, which produces a wider consciousness.

\subsection{Planner as a mediator: political area}

Considering the role of this practitioner as a professional, with just relational and technical skills, would mean renouncing to some of his/her most relevant and peculiar characteristics. 
If we read again the previously mentioned elements for relational and technical areas, we would probably agree on the continuous presence of a political dimension that can't be avoided.

Although knowhow can structure effective relationships and networks, or skills can be learned studying and training in their specific fields, what further define the planner's professional approach are experience, creativity and personal involvement. These are otherwise the interpretive skills of a reflective practitioner [4].

Considering the case with patronage in public administration and planning professionals in the formal role of integrated consultants, we can keep an eye on the relationship between them and the political and institutional context, wondering what inclusion and collaboration mean, what kind of conflicts are represented by powers, what stakes hide behind different positions [5], what accountability to institutions. Questions like these enlighten us on a better definition of a practitioner's autonomy (related to his/her authority and reliability).

\section{The case: Roma V 2030}

In March 2015, a collaborative strategic planning experience, called Roma V 2030, started with the sponsorship of one of the fifteen districts of Rome. In that time, the 5th Roman municipality (municipio) got two consultants via an interinstitutions contract, specifically with the Region of Lazio, to apply the competences of these two, an urban planner and an anthropologist, both with international experience in facilitating territorial inclusive policies.

The policy design has been conceived in cooperation with the Municipal Councillor responsible for planning and mobility, and the Municipal Councillor for environment, inter-culture and innovation of public administration.

The idea of developing an investigation process about this territory, starting from the present and looking fifteen years ahead, stems from the local administration in need to include the citizenship's daily stimuli, often oriented to contingent emergencies, in a wider framework of local policies, especially after the territorial reform of the Roman municipalities of 2013. This reform reduced the number of municipalities melting, in most of the cases, two previous municipalities (or parts of) having distinct and different territorial services. The immediate result was, and partially still is, a difficult administrative and territorial readjustment.

In the same months the project called Roma Resiliente also started, as a part of the wider 100 Resilient Cities, an international network of cities working on urban resilience, promoted by the Rockefeller Foundation. This policy has been improved by the city of Rome, which defined Roma V 2030 a local and operational process to develop a better knowledge about urban resilience. During the 8 months of Roma V 2030, the two projects shared tools and resources, giving each other support in terms of theoretic (Roma Resiliente) and practical (Roma V 2030) knowledge. 


\subsection{Process structure}

Roma V 2030 was structured in three phases [6]:

1. Preparation and investigation, with more than 20 open interviews with 'privileged witnesses' (also called experts of the territory), questionnaires (printed and distributed in the spontaneous aggregation sites and online the website) and maps to identify the perception of neighbourhoods' boundaries in the fifth municipality.

2. Workshops, or 9 focus groups called city $L A B$, discussing about the municipal land according to the specific perspective related to the involved groups, emerged during the first phase.

3. Restitution, which provides for the data processing for the identification of municipal strategies related to groups and territorial trends. The emerging municipal resilience brings to an assuming political act of the fifth municipality's council, which acquires the results in order to improve future local policies.

\subsection{Those who live in the territory}

Starting elaborated data about the municipality were produced by the urbanism department of Rome, during an investigation process called Conferenze urbanistiche [7].

With 245,000 inhabitants, the fifth municipality of Rome (Municipio Roma V) represents $9 \%$ of the Roman population, in an area that corresponds to $2 \%$ of the Roman territory. In this land, along with wide green extensions, there are some areas, which have the highest rate of population density in Rome.

Relevant also is the data concerning per age group stratification of the population: where over 65 decrease, over 85 increase, which is almost twice the average of the city $(21.7 \%$ against the $11.7 \%)$.

Like many areas of the city of Rome, this territory was created to locate Italian immigrants, coming mostly from the south, at the beginning of the XX century, and subsequently after the two world wars. In the late 80 s and early 90 s, the first migration from Eastern Europe started in Rome, and in the current fifth municipality. Today there are three huge Roma camps in this municipality, where just one is regularly equipped, while two are spontaneous.

Since the late 90s, Rome saw many migratory flows from Africa, Asia and the South-America. The fifth municipality has a higher citywide attendance rate of migrant population: between 2008 and 2013, the foreign population residing in the municipality increased by $35.1 \%$, compared to a city average of $23.3 \%$.

\section{Process outcomes}

The tools of the process gave the chance to develop two categories of thought about the present, with strengths and weaknesses, and about the future, discussing strategies to implement or improve what there is today. 
Then, both of these dimensions were translated in cartographies: these weren't the aim of the process, but a way to resume some of the relevant topics, pointing them on the territorial scale of the fifth municipality.

\subsection{Strengths and weaknesses}

While meeting the citizenship, the territory was the subject of debates to understand multiple perceptions. Some topics were continuously highlighted as the most important, to describe their municipality:

- The enhancement of archaeological and green heritage, until the traces of neorealist cinema;

- The value of belonging, often related to a sense of land care for their neighbourhoods.

These elements are strongly connected to each other, as heritage is one of the biggest reasons of pride in belonging, no matter in which scale. Everyone can easily imagine the pride of Romans about their city, as it can happen for Parisians or New Yorkers. The same happens also on the neighbourhood scale, in which the community can get to know itself, thanks to proximity although its territory (27 square kilometres) is probably too huge as a neighbourhood and too small to be felt as a city itself. Citizens consider now, after the merging, the municipality a mere administrative entity, as emerged during public meetings. The loss of a geographical perception of the municipality from the citizens, lead to a lack of contact with the territory itself.

The management of valuable elements, available in the municipality, are revealed as the biggest weakness, mostly because the economical resources are not determined by the single municipalities but by general city council. This is how strength is perceived in the same time as a deep weakness, since people can clearly see its potential.

Other emerging issues:

- The contradictory social cohesion, related to migrations and different ages: integration is for many a precious element able to enrich their territory, for others it represents a difficulty and even a problem to deal with in everyday life;

- A feeble political cohesion, as the relationship between citizenship (groups or individuals) and institutions and between different groups of people: this is a very active territory, where many groups continuously increase the social capital. For example: there are many associations and organizations working in the broad field of intercultural dialogue and integration. They provide many services in the area, although they are not organized on explicit needs coming from the administration. They often live with limited resources and volunteering;

- Productivity and innovation: since its industrial and manufacturing history, the municipal territory still owns some professional traditions that some citizens don't want to lose. Next to the craft skills, there is a spread of new forms of work, such as co-working and fab-lab, linked to young professionals as 'digital artisans'; 
- Mobility and public transportation, with the huge presence of rails (tramways, metro, urban train) and the lack of capillary buses and bicycle paths, which would improve a more sustainable mobility.

\subsection{Municipal strategies}

The 9 thematic workshops have been conceived as focus groups, to elaborate the elements emerged during the open interviews and the questionnaires. These groups, composed by citizens as individuals or representing associations or organizations, worked on the identification of main developing strategies and future policies for the municipality, mentioning also the related already existing actions they knew about.

A diagram of strategies detected as priorities follows, and corresponding implementing actions. Strategies were also grouped into three main categories: people, tools and places.

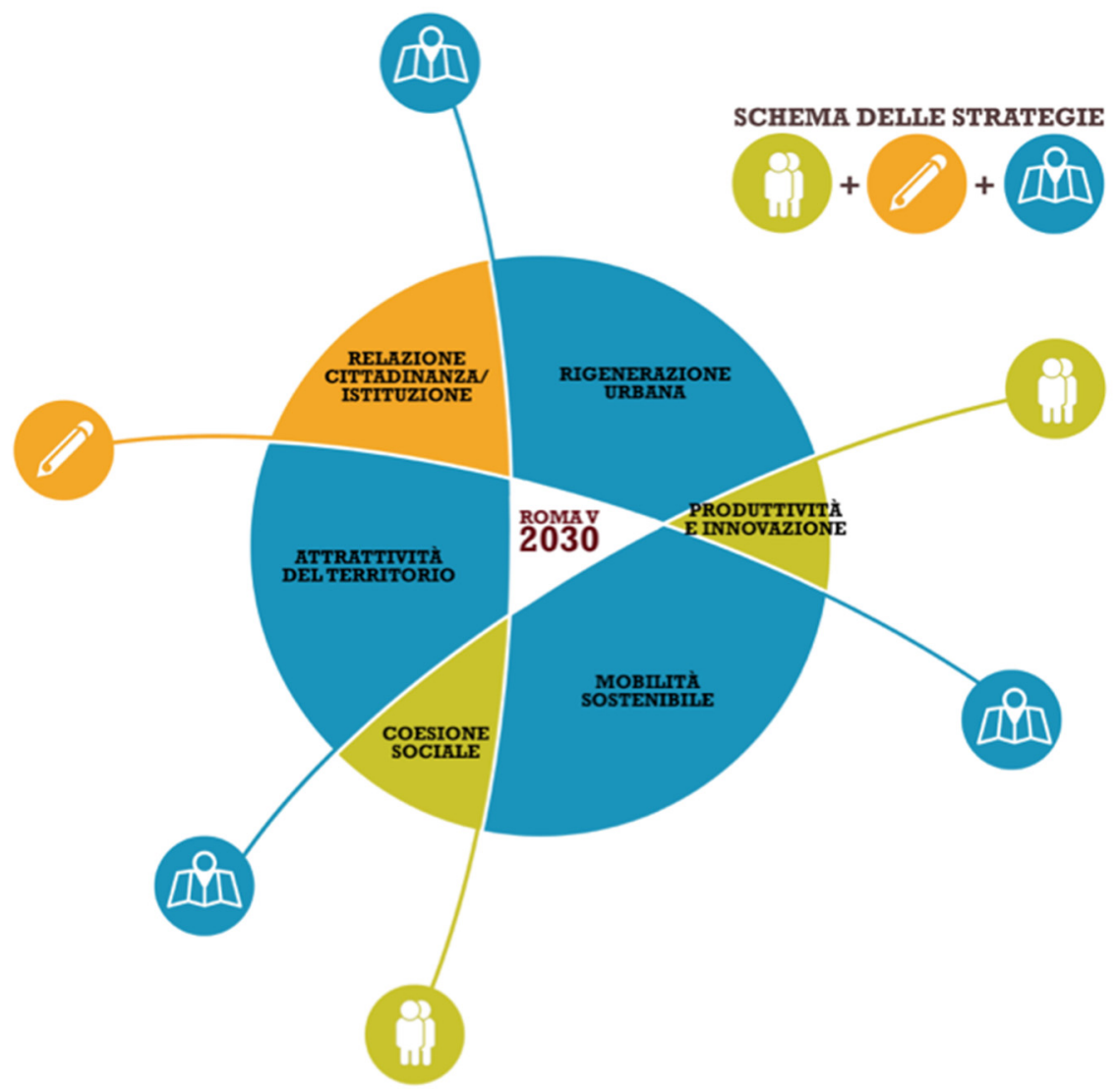

Figure 1: Diagram of Roma V 2030 strategies. 


\subsubsection{Urban regeneration}

Urban regeneration clearly emerged in the debate on the municipal territory, considering a rehabilitation perspective of conserving the existing tissue, rather than the progressive deterioration by inconsistent speculative operations.

The limitation of land use can therefore pass through a better awareness of the public and private abandoned industrial sites (derelict heritage), as well as of the reasons for its state of abandon. Territorial policies of regeneration may allow the development of new management strategies, different models from those hitherto used, or exploring new public-private partnerships.

\subsubsection{Territory attractiveness}

With the increasing attention to the heritage of this area and in relation with the territorial regeneration, it is necessary to consider the fundamental preservation of green spaces and historical and archaeological artefacts. Use and accessibility need to be taken into account, emphasising improvement measures where necessary, for the inhabitants of the fifth municipality and the touristic potential. For example, interventions of sustainable mobility - such as a bike lane - allow accessibility to places of historical and archaeological interest: this is a way to focus on the existing wealth, bringing a common enhancement to cultural and natural places.

\subsubsection{Social cohesion}

Among data related to social cohesion, some trends were considered as peculiar features of this municipality: active aging, for instance, expressed the need for new integrative, inter-generational and cultural activities. Some policies are also needed to make the municipal land more suitable for children: a family-friendly city.

Social cohesion concerns inter-culture, too. Numerous associations and organizations work in this sector, creating courses, events, festivals, and places for encounter and exchange between cultures and, finally, even generations. For this reason, it is proposed the possibility of establishing a network of stakeholders in the field of inter-culture, because through them and their profession it is possible to make up the regenerated tissue of the municipal community.

\subsubsection{Citizenship Report/institutions}

As Roma $V 2030$ belongs to this strategic sector, it emerged the need of the local public administration to develop more strategic policies. Collaborative processes should ensure some continuity in front of its public, not being a temporary reference without implementation. This is why a continuous development of strategic and integrated planning needs to move with changing needs of the population and politics. It is also relevant the need of improvement of interdepartmental relationships within the local authority, as well as those with the central government. These aims need to be pursued with intent of transparency and cooperation with the citizens, in order to implement more efficient policies in public administration, whether local or territorial. 


\subsubsection{Productivity and innovation}

The highly stimulating initiatives of digital crafts, co-working spaces, small businesses and start-ups has a great potential in terms of professional, economic and productive impact. Organized in a network, with a physical or virtual location, they could find a significant enhancement in reciprocity and partnerships with each other.

Traditional craftsmanship could find a new impetus in the establishment of training centres. An example of these projects: in the almost abandoned warehouses of the Roman opera house, a sound stage could be realized, with a working space for professionals related to theatre (from set designer to tailor).

The enhancement of knowledge and know-hows can develop the local traditional expertise, building new opportunities too.

\subsubsection{Sustainable mobility}

The debate on sustainable mobility led to some awareness on municipal territory to predict suitable actions to enhance the existing features. Since rails are so present, but not often used, because perceived as unsecure, some incentive policy can promote them. Soft mobility is also seen as a priority, through the establishment of Zone 30 (areas for vehicular circulation with $30 \mathrm{~km} / \mathrm{h}$ speed limit), bicycle paths and bike lanes.

\subsection{Strategic cartographies}

The data, emerging from the territorial laboratories, have enabled the development of maps related to some of the previously described strategies. They represent some of the results from the public debate with citizens and administrators during Rome V 2030 between March and October 2015.

These maps are updatable tools, to evolve with municipal policies, concerning three territorial perspectives, from the emerged strategies:

- Regeneration: representing the public or private property to regenerate, by demolition and reconstruction or re-functionalization intervening on architecture or urban fabric. There are also represented areas to preserve, related to the maintenance of green areas.

- Mobility: highlighting the collective reflection about sustainability in local transportation.

- Attractiveness: underlining the large number of historical and archaeological artefacts, often next to recent and popular forms of street art, which could be matched in different and mixed touristic paths.

\section{Evaluation of the process}

\subsection{Belonging and resilience as strategic planning}

In this case study, the relationship with people was built around their perception of the valuable elements of the territory.

We must define, first of all, what is territorial belonging: it is matter of defining identity in everyday life, even considering historical and environmental characters. 
Meanwhile, for resilience we mean the social and urban reaction, able to produce changes and to restore recognizable values in the surrounding territorial elements.

Roma $\mathrm{V} 2030$ has been a way to study and represent its territory identifying its peculiarities, bringing the citizen on the stage, to deliver to the administration a more attentive picture. Policies could start then from a more conscious knowledge of needs and cares of people.

This case met the support of many public offices in the fifth municipality, but also some suspicions at the beginning with some administrators and citizens. Suspicions caused mainly by the dissatisfaction lived in this local scale, which hasn't wide tools to manage the city, in this lack of local autonomy. With time, trust has been achieved with the most of them, and others adopted some detachment.

Finally, a municipal act was formally registered, with a final report on strategies and the strategic cartographies.

This is how we can consider belonging as a tool for strategic planning, by inclusive methods from social research. Listening to stories from people is a way to collect the territorial heritage, mostly neighbourhood-related. Some 'unbreakable bonds' with territory, as some participant said, are important resources at the disposal of planners.

\subsection{Networking as implementation}

Belonging becomes resilient with independent actions of networking, in this case related to the field of productivity. Co-working and $f a b$-lab, as informal groups of citizens, find necessary to integrate the innovations they produce with the areas in which they develop them, to become a resource for the municipal development too.

That is why we can see, after the end of Roma $\mathrm{V} 2030$, the relevance of the birth of CoRete (coreteroma.org), a network of collaborative productive structures in the municipality and on communal scale, including all the organizations and their practical knowledge sharing value with their own spontaneous activity from below, contributing to a sustainable growth.

On the other hand, after the end of Roma $V$ 2030, a closer connection has been built between the public administration and UnIndustria, the local association of enterprises and factories of the Region of Lazio, which has the head office in the fifth municipalities, as many factories. With some round tables for consultation, the public administration has met in last months these interlocutors, to develop project together with private contribution, also considering the needs emerged in this inclusive process. Still some operative activities are developing, even if in June 2016 there will be communal and municipal election in Rome. It will be possible to observe if the next municipal council can take account of these progresses and links with the territory. 


\subsection{Role of planner in belonging development}

Among the main characteristics related to professionals of planning, described at the beginning of this paper, there are some that can be kept and better defined by this case.

At the very beginning, the planners listened to the exigencies of this municipal public administration, understanding a need of getting closer to the citizenship to find a partner in defining a local political consciousness. The relevant aspect in this case has been the practice's condition: the paucity of human and economic resources for developing a deeper analysis and interaction with this territory.

The practitioners - both planners, even if they one is an urbanist and the other anthropologist - have faced continuously the need of adaptability. The available instruments and the discontinuous facility to have the access to data, such as contacts or previous collected information, required the capability to change the expected operative actions. The reflection in and on action, as Schön showed, is the elastic skill to improve the practitioner's creativity [8].

This is furthermore possible, thanks to the deployment of a basic combination of experience and common sense. A strategic and organizational thinking is improved, by the relational, technical and political skills above described, to define a professional as a 'planner'. Planning is not a matter of plans as cartographies and charts, but of trust, responsibility and adaptability in designing and accompanying public policies.

\section{Conclusions}

Roma V 2030 was the opportunity to develop tools for the practitioner of inclusive policies. Among these tools, we find how belonging and urban resilience are the citizens' expression in collaborative approaches. History and peculiar territorial characteristics are collectively recognizable by those who live the territory, but this experiment expressed the need of protection and improvement of their own land.

The aims of collaboration, among others, are collective learning, improvement of community awareness and empowerment. But, for impacting the public goods, we need a deeper consciousness, in order to administrate, plan and share them, avoiding the spread of free-riding problem.

Sensitive public administrations, collaborative citizenship and reflective practitioners are three necessary elements to build an integrated process of coordination, which encourages the responsibility assumption of impacting the commons.

\section{References}

[1] Forester, J., The Deliberative Practitioner: Encouraging Participatory Planning Processes, The MIT Press, 1999.

[2] Bourdieu, P., Wacquant, L., An Invitation to Reflexive Sociology, University of Chicago Press, trans. Wacquant, 1992. 
[3] J. Forester, Responding to critical moments with humor, recognition, and hope, Negotiation Journal, vol. 20, no. 2. pp. 221-237, 2004.

[4] D. Schön, The Reflective Practitioner: How professional think in action, Basic Books, 1984.

[5] Sclavi, M., Susskind, L.E., Confronto creativo. Dal diritto di parola al diritto di essere ascoltati, Et Al, 2011.

[6] https://www.comune.roma.it/pcr/it/newsview.page?contentId=NEW878667

[7] http://www.urbanistica.comune.roma.it/conf-urb-municipio5.html

[8] Forester, J., Planning in the Face of Conflict: The Surprising Possibilities of Facilitative Leadership, APA Planners Press, 2013. 